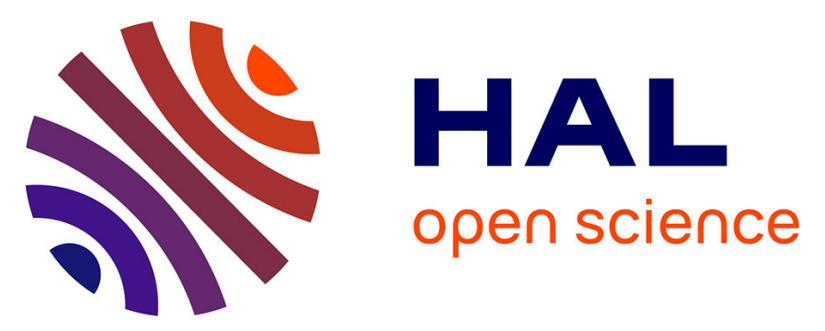

\title{
Low risk of invasive lobular carcinoma of the breast in carriers of BRCA1 (hereditary breast and ovarian cancer) and TP53 (Li-Fraumeni syndrome) germline mutations
}

Yoan Ditchi, Chloé Broudin, Yolla El Dakdouki, Marie Muller, Pernelle

Lavaud, Olivier Caron, Donia Lejri, Caroline Baynes, Marie-Christine

Mathieu, Julia Salleron, et al.

\section{- To cite this version:}

Yoan Ditchi, Chloé Broudin, Yolla El Dakdouki, Marie Muller, Pernelle Lavaud, et al.. Low risk of invasive lobular carcinoma of the breast in carriers of BRCA1 (hereditary breast and ovarian cancer) and TP53 (Li-Fraumeni syndrome) germline mutations. The Breast Journal, 2019, 25 (1), pp.16-19. 10.1111/tbj.13154 . hal-02352242

\section{HAL Id: hal-02352242 \\ https: / hal.sorbonne-universite.fr/hal-02352242}

Submitted on 6 Nov 2019

HAL is a multi-disciplinary open access archive for the deposit and dissemination of scientific research documents, whether they are published or not. The documents may come from teaching and research institutions in France or abroad, or from public or private research centers.
L'archive ouverte pluridisciplinaire HAL, est destinée au dépôt et à la diffusion de documents scientifiques de niveau recherche, publiés ou non, émanant des établissements d'enseignement et de recherche français ou étrangers, des laboratoires publics ou privés. 


\section{Low Risk of Invasive Lobular Carcinoma of the Breast in carriers of BRCA1 (hereditary breast and ovarian cancer) and TP53 (Li-Fraumeni syndrome) germline mutations}

Yoan Ditchi ${ }^{1}$, Chloé Broudin ${ }^{1}$, Yolla El Dakdouki ${ }^{1}$, Marie Muller ${ }^{1,2}$, Pernelle Lavaud ${ }^{1}$, Olivier Caron ${ }^{1}$, Donia Lejri ${ }^{1}$, Caroline Baynes ${ }^{3,}$ Marie-Christine Mathieu ${ }^{4}$, Julia Salleron ${ }^{5}$, Patrick R. Benusiglio ${ }^{1,6 *}$.

1. Département de Médecine Oncologique, Gustave Roussy, Université Paris-Saclay, Villejuif, F94805, France

2. Département de Médecine Oncologique, Institut de Cancérologie de Lorraine Alexis Vautrin, Vandœuvre-lès-Nancy, F-54519, France

3. Department of Oncology, Strangeways Research Laboratory, University of Cambridge, Worts Causeway, Cambridge CB1 8RN, United Kingdom

4. Département de Biologie et Pathologie Médicales, Gustave Roussy, Université Paris-Saclay, Villejuif, F-94805, France

5. Département de Biostatistiques, Institut de Cancérologie de Lorraine Alexis Vautrin, Vandœuvrelès-Nancy, F-54519, France

6. Consultation d'Oncogénétique, UF d'Oncogénétique, Groupe Hospitalier Pitié-Salpêtrière APHP, F-75013 Paris, France

* Corresponding author

Postal address

Consultation d'Oncogénétique, UF d’Oncogénétique

Département de Génétique

Groupe Hospitalier Pitié Salpêtrière APHP

47-83 Boulevard de l’Hôpital

75013 Paris, France

Emails patrick.benusiglio@cantab.net, patrick.benusiglio@aphp.fr

Keywords : BRCA1, BRCA2, invasive lobular carcinoma of the breast, genetic susceptibility to disease, Li-Fraumeni syndrome, TP53.

Link to published version: https://onlinelibrary.wiley.com/doi/full/10.1111/tbj.13154 


\begin{abstract}
Background. Invasive lobular carcinoma (ILC) of the breast has epidemiological, molecular and clinical specificities, and should likely be considered a unique entity. As for genetic susceptibility, CDH1 germline mutations predispose exclusively to ILC. Data are however scarce regarding ILC in women with BRCA1/2 (Hereditary Breast and Ovarian Cancer) and TP53 (Li-Fraumeni syndrome) germline mutations. Methods. We included all breast cancers from female patients tested at our Institute between 1992 and 2016 ( $n=3469)$ for which pathology data were available. ILC proportion comparison according to mutational status was performed by a Chi-squared test. The impact of susceptibility genes on ILC proportion was investigated by univariate logistic regression with wildtype patients as reference. Results and Discussion. There were 265 (7.64\%) ILC: 2/342 (0.58\%) in BRCA1 patients, 24/238 (10\%) in BRCA2 patients, $1 / 57$ (1.75\%) in TP53 patients and 238/2832 (8.4\%) in non-carriers. The majority of breast cancers in all groups were invasive ductal and ductal in situ carcinomas. The difference in ILC proportion was highly significant $(p<0.001)$. Compared to wild-type patients, BRCA1 was associated with a lower ILC proportion (OR 0.064 [95\% $\mathrm{Cl} 0.016 ; 0.259], \mathrm{p}<.0001$ ). BRCA2 OR was 1.222 [95\% Cl $0.785 ; 1.902](p=0.374)$, TP53 OR was $0.195[95 \% \mathrm{Cl} 0.027 ; 1.412]$ $(p=0.105)$. ILC are therefore underrepresented in BRCA1 and TP53 mutation carriers. Formal significance $(p=0.05)$ was not reached for TP53, but statistical power was only $38 \%$. Based on ILC incidence in the general population, we make the hypothesis that BRCA1 and TP53 do not predispose to ILC, as the few occurrences of ILC in mutation carriers could be attributed to chance and not to germline mutations. Our observations will be useful to clinical cancer geneticists managing patients with ILC, as a BRCA1 or TP53 mutation in these patients would be unlikely. Genetic counselling should be adapted accordingly,
\end{abstract}




\section{Introduction}

Invasive lobular carcinomas (ILC) represent about $10 \%$ of invasive breast cancers ${ }^{1,2}$, while the remainder are mostly ductal carcinomas (IDC), also called invasive carcinomas of no special type. Recent data support the notion that ILC is a disease with epidemiological, molecular and clinical specificities, and that it should be considered a unique entity among breast cancers. For example, menopausal hormone therapy is more strongly related to the risk of ILC compared to IDC, regardless of hormone receptor status ${ }^{3}$. In a comprehensive molecular profile of 817 breast cancers, Ciriello et al. observed CDH1 and PTEN loss, AKT activation, and mutations in TBX3 and FOXA1 in ILC, and showed that these profiles were not seen in IDC ${ }^{4}$. Finally, in the BIG 1-98 study, the magnitude of benefit of adjuvant hormone therapy was greater for patients diagnosed with ILC versus IDC ${ }^{5}$.

As for genetic susceptibility to breast cancer, there are plenty of gaps to fill with regard to ILC. While it is now accepted that germline mutations in $C D H 1$, the breast and diffuse gastric cancer susceptibility gene, predispose exclusively to ILC ${ }^{6,7}$, data are scarce regarding women with germline mutations in the other major genes, more specifically BRCA1/2 (hereditary breast and ovarian cancer) and TP53 (Li-Fraumeni syndrome). For example, even the largest and most comprehensive work on histopathological breast cancer features in BRCA1/2 mutation carriers only focused on hormone receptors and grade without making any mention of type ${ }^{8}$. Of note, $\mathrm{CDH} 1$ is the only ILCspecific susceptibility gene, along with a common, low-penetrance polymorphism at the 7q34 locus ${ }^{9}$.

In this study, we collected data on 3469 consecutive breast cancers diagnosed in female patients. We compared 637 cancers in carriers of BRCA1, BRCA2 and TP53 germline mutations with 2832 cancers in non-carriers (wild-type patients) regarding ILC frequency. We show that ILC is underrepresented in carriers of BRCA1 and TP53 mutations. Given the rarity of ILC in these patients, we also make the hypothesis that their risk of ILC is close to, if not similar, to the general population risk. Our observations strengthen the hypothesis that even though both are invasive epithelial breast carcinomas, ILC and IDC are different diseases.

\section{Patients and methods}

We included all consecutive invasive and ductal in situ breast cancers diagnosed in female patients tested at our Cancer Genetics Clinic (Gustave Roussy Cancer Institute, Villejuif, France) between 1992 and 2016, and for which pathology data were available. Patients had been referred to us when cancer susceptibility was suspected, e.g. breast cancer $\leq$ age 40 , breast cancer with one relative with breast cancer $\leq 50$, or breast cancer with a relative with ovarian cancer for BRCA1/2, classical LiFraumeni criteria, Chompret criteria, or breast cancer $\leq$ age 30 for TP53 ${ }^{10,11}$. Informed consent was obtained, and germline DNA testing was performed using different methods depending on the period, e.g. SSCP, fluorescence, Sanger and NGS sequencing, qPCR and MLPA. 
Statistical analyses were carried out with the SAS software (SAS Institute Inc., Cary, NC, USA.). The significance level was set at 0.05 . The comparison of ILC proportion according to mutational status was performed by a Chi-squared test. The impact of susceptibility genes on ILC proportion was investigated by univariate logistic regression with wild-type patients as reference. Results were expressed by odds ratio (OR) and $95 \%$ confidence interval.

\section{Results}

We included 3469 breast cancers. Of these, 637 (18.36\%) were from mutation carriers: 342 (9.86\%), 238 (6.86\%) and 57 (1.64\%) from BRCA1, BRCA2, and TP53 patients respectively. The remaining 2832 had been diagnosed in wild-type patients. There were 265 (7.64\%) ILC: 2/342 (0.58\%) in BRCA1 patients, 24/238 (10\%) in BRCA2 patients, $1 / 57$ (1.75\%) in TP53 patients and 238/2832 (8.4\%) in noncarriers (table 1). The difference in ILC proportion according to the mutational status was highly significant $(p<0.001)$. Compared to wild-type patients, BRCA1 was significantly associated with a lower proportion of ILC (OR 0.064 [95\%Cl $0.016 ; 0.259], \mathrm{p}<.0001)$. BRCA2 OR was 1.222 [95\% 0.785 ; 1.902] $(p=0.374)$ and TP53 OR was $0.195[95 \% \mathrm{Cl} 0.027 ; 1.412](p=0.105)$. As expected, the overwhelming majority of breast cancers in all groups were IDC and ductal in situ carcinomas: 327/342 (96\%) in BRCA1 patients, 54/57 (95\%) in TP53 patients, 204/238 (86\%) in BRCA2 patients and $2490 / 2832(88 \%)$ in non-carriers, the remainder being mostly rare types such as medullary, mucinous, papillary or tubular carcinomas, there was also one case of mixed ductal-lobular cancer (in a BRCA1 patient), and obviously the above-mentioned ILC.

\section{Discussion}

In this retrospective study of nearly 3500 breast cancers, the difference in ILC proportion according to the mutational status was highly significant. ILC was significantly underrepresented in BRCA1 mutation carriers compared to wild-type patients with an OR of $0.064(p<0.0001)$. TP53 germline mutations were associated with an $80 \%$ reduction in the odds of ILC (OR=0.195), admittedly with a $p$ value of 0.105 , meaning we came close but did not reach significance. That should not be a reason to dismiss our results as we only had $38 \%$ statistical power to detect a difference at the consensus 0.05 level. One hundred and twelve breast cancers in patients with TP53 mutations out of a total sample size of 6769 would have been required in order to have $80 \%$ power, but that would be hard to achieve without multicentre collaborations considering the rarity of Li-Fraumeni. Furthermore, the OR were lower than 0.3 and therefore indicate a strong relationship with ILC, suggesting a real, meaningful difference between the two groups ${ }^{12}$. There were no differences for BRCA2.

Surprisingly, the issue of breast cancer type in patients with genetic susceptibility to the disease is hardly addressed in the literature, the most striking example being the large, multi- 
consortia study by Spurdle et al. published in 2014 and based on 54607 breast cancer cases ${ }^{8}$. The authors compared hormone receptor, HER2, CK5/6 status, and grade in BRCA1 patients, BRCA2 patients and non-carriers, but nowhere in the article did they mention cancer type. In an earlier paper, the CIMBA consortium reported, amongst other characteristics, breast cancer type and showed that ILC was more likely to be associated with BRCA2 compared to BRCA1 ${ }^{13}$. However, this observation was apparently considered of minor importance since it did not feature in the discussion. Furthermore, there was no comparison with non-carriers. On the contrary, we did have control subjects (our non-carriers) from the same population as cases and recruited under similar conditions. There is a similar phenomenon regarding Li-Fraumeni. Two recent studies evaluated 415 French and 286 US patients, and reported 172 and 118 breast cancers, respectively ${ }^{14,15}$. No mention was made of tumour type. In 2012, Masciari et al. performed a central review of 43 breast cancers from Li-Fraumeni patients and only observed ductal histologies ${ }^{16}$. Like in the CIMBA study, the absence of ILC was not addressed in the discussion, neither was it in the abstract, and the emphasis was put on hormone receptor and HER2 status. There was no comparison with tumours in noncarriers either.

Somatic studies support our observations. Indeed, in large-scale molecular portraits of ILC, alterations in both BRCA1 and TP53 are rare in ILC, and underrepresented compared to IDC ${ }^{4,17}$. Only two BRCA1 and 31 TP53 mutations were observed in 413 ILC in the Desmedt paper vs. for example 285 and 182 in the classical ILC genes CDH1 and PIK3CA. In the Ciriello paper, TP53 alterations were present in $8 \%$ of ILC vs. $44 \%$ of IDC $\left(q=1.9 \mathrm{e}^{-14}\right)$, there were no data for BRCA1. These molecular portraits show that different oncogenic pathways are involved in ILC/IDC development, and that BRCA1 and TP53 are likely of minor importance in ILC.

The question raised by our results is whether BRCA1 and TP53 predispose to ILC at all. Our data do not allow for definitive conclusions, but we make the hypothesis they do not. Indeed, estimates for average annual breast cancer incidence in the general population are $118 / 100^{\prime} 000^{18}$. For BRCA1, our patients had an average age of 51.3 at last follow up. Combining incidence and last follow up, nineteen breast cancers would have been expected, two of them (10\%) ILC. This is exactly the observed number in our study. As for TP53, it is conceivable that one single occurrence of ILC could be due to chance, even more so considering that the only patient with ILC was diagnosed at the age of 55, while breast cancers in Li-Fraumeni are commonly seen in very young patients ${ }^{14}$.

Our observations have direct implications for clinical cancer geneticists. Indeed, they will now be aware that a BRCA1 or TP53 mutation is unlikely in a patient with ILC. Genetic counselling should be adapted accordingly, i.e. no mention of a possible $>40 \%$ lifetime risk of ovarian cancer as seen with BRCA1 or of a potential risk of multiple cancers regardless of age as seen in Li-Fraumeni 
syndrome ${ }^{19}$. Patients might experience reduced stress levels as a result, considering the welldocumented physical and psychological consequences of ovarian and of Li-Fraumeni-associated cancers $^{20-22}$.

Compared to other cancers (IDC included), ILC shows unusually high levels of familial clustering, pointing towards a major contribution of genetic, inherited factors to the disease ${ }^{23}$. Only one clinically relevant ILC-specific susceptibility gene, $C D H 1$, has been identified so far. The possibly null, at best minor, implication of BRCA1 and TP53 in ILC causality tells us there is a lot to discover regarding genetic susceptibility to ILC. We hope whole exome sequencing studies in ILC families will soon provide an answer. Our observations on the genetic specificities of ILC are all the more relevant today. Indeed, researchers and clinicians are finally starting to give ILC the importance it deserves, as illustrated for example by the first International ILC Symposium held last year in Pittsburgh (https://upci.upmc.edu/wcrc/ilcsymposium-info.cfm). Even though both are invasive epithelial breast carcinomas, ILC and IDC should likely be considered different diseases. 


\begin{tabular}{|c|c|c|c|c|c|}
\hline & $\begin{array}{l}\text { No } \\
\text { mutation }\end{array}$ & BRCA1 & BRCA2 & TP53 & Total \\
\hline $\begin{array}{l}\text { Total breast } \\
\text { cancers }\end{array}$ & 2832 & 342 & 238 & 57 & 3469 \\
\hline ILC & $238(8.40 \%)$ & $2(0.58 \%)$ & 24 (10\%) & 1 (1.75\%) & 265 \\
\hline $\begin{array}{l}\text { Other } \\
\text { histologies }\end{array}$ & 2594 & 340 & 214 & 56 & 3204 \\
\hline OR [95\%Cl] & 1 (ref) & $\begin{array}{l}0.064 \\
{[0.016 ; 0.259]}\end{array}$ & $\begin{array}{l}1.222 \\
{[0.785 ; 1.902]}\end{array}$ & $\begin{array}{l}0.195 \\
{[0.027 ; 1.412]}\end{array}$ & \\
\hline p-value & & $<0.001$ & 0.374 & 0.105 & \\
\hline
\end{tabular}

Table 1. Invasive lobular carcinoma (ILC) and other types according to germline mutations in major susceptibility genes. Odds Ratios (OR) represent the risk of ILC in mutation carriers vs. patients with no mutation. 


\section{REFERENCES}

1. Li C, Uribe D, Daling J. Clinical characteristics of different histologic types of breast cancer. $\mathrm{Br}$ J Cancer. 2005;93(9):1046-1052.

2. $\quad \mathrm{Li} \mathrm{Cl}$, Anderson BO, Daling JR, et al. Trends in Incidence Rates of Invasive Lobular and Ductal Breast Carcinoma. JAMA. 2003;289(11):1421.

3. $\mathrm{Li} \mathrm{Cl}$, Daling JR, Haugen KL, et al. Use of menopausal hormone therapy and risk of ductal and lobular breast cancer among women $55-74$ years of age. Breast Cancer Res Treat. 2014;145(2):481-489.

4. Ciriello G, Gatza ML, Beck AH, et al. Comprehensive Molecular Portraits of Invasive Lobular Breast Cancer. Cell. 2015;163(2):506-519.

5. Metzger-Filho O, Giobbie-Hurder A, Mallon E, et al. Relative effectiveness of letrozole compared with tamoxifen for patients with lobular carcinoma in the BIG 1-98 Trial. J Clin Oncol. 2015;33(25):2772-2778.

6. Benusiglio PR, Colas C, Rouleau E, et al. Hereditary diffuse gastric cancer syndrome: Improved performances of the 2015 testing criteria for the identification of probands with a CDH1 germline mutation. J Med Genet. 2015;52(8).

7. Hansford S, Kaurah $\mathrm{P}$, Li-Chang $\mathrm{H}$, et al. Hereditary Diffuse Gastric Cancer Syndrome: CDH1 Mutations and Beyond. JAMA Oncol. 2015;1(1):23-32.

8. Spurdle AB, Couch FJ, Parsons MT, et al. Refined histopathological predictors of BRCA1 and BRCA2mutation status: a large-scale analysis of breast cancer characteristics from the BCAC, CIMBA, and ENIGMA consortia. Breast Cancer Res. 2014;16(6):3419.

9. Sawyer E, Roylance R, Petridis C, et al. Genetic Predisposition to In Situ and Invasive Lobular Carcinoma of the Breast. Gibson G, ed. PLoS Genet. 2014;10(4):e1004285.

10. Li FP, Fraumeni JF, Mulvihill JJ, et al. A cancer family syndrome in twenty-four kindreds. Cancer Res. 1988;48(18):5358-5362.

11. Tinat J, Bougeard G, Baert-Desurmont S, et al. 2009 Version of the Chompret Criteria for Li Fraumeni Syndrome. J Clin Oncol. 2009;27(26):e108-9; author reply e110.

12. Haddock C, Rindskopf D, Shadish WR. Using odds ratios as effect sizes for meta-analysis of dichotomous data: A primer on methods and issues. Psychol Methods. 1998;3(3):339-353.

13. Mavaddat N, Barrowdale D, Andrulis IL, et al. Pathology of breast and ovarian cancers among BRCA1 and BRCA2 mutation carriers: Results from the consortium of investigators of modifiers of BRCA1/2 (CIMBA). Cancer Epidemiol Biomarkers Prev. 2012;21(1):134-147.

14. Bougeard G, Renaux-Petel M, Flaman J-M, et al. Revisiting Li-Fraumeni syndrome from TP53 mutation carriers. J Clin Oncol. 2015;33(21).

15. Mai PL, Best AF, Peters JA, et al. Risks of first and subsequent cancers among TP53 mutation carriers in the National Cancer Institute Li-Fraumeni syndrome cohort. Cancer. 2016;122(23):3673-3681.

16. Masciari S, Dillon DA, Rath M, et al. Breast cancer phenotype in women with TP53 germline mutations: A Li-Fraumeni syndrome consortium effort. Breast Cancer Res Treat.

2012;133(3):1125-1130. 
17. Desmedt C, Zoppoli G, Gundem G, et al. Genomic Characterization of Primary Invasive Lobular Breast Cancer. J Clin Oncol. 2016;34(16):1872-1881.

18. Binder-Foucard F. Estimation Nationale de L'incidence et de La Mortalité Par Cancer En France Entre 1980 et 2012. Institut de Veille Sanitaire; 2013.

19. Kuchenbaecker KB, Hopper JL, Barnes DR, et al. Risks of Breast, Ovarian, and Contralateral Breast Cancer for BRCA1 and BRCA2 Mutation Carriers. JAMA. 2017;317(23):2402.

20 Vitale SG, Marilli I, Lodato M, Tropea A, Cianci A. The role of cytoreductive surgery in advanced-stage ovarian cancer: a systematic review. Updates Surg. 2013;65(4):265-70.

21 Mielcarek P, Nowicka-Sauer K, Kozaka J. Anxiety and depression in patients with advanced ovarian cancer: a prospective study. J Psychosom Obstet Gynaecol. 2016;37(2):57-67.

22 Lammens CR, Aaronson NK, Wagner A, Sijmons RH, Ausems MG, Vriends AH, Ruijs MW, van Os TA, Spruijt L, Gómez García EB, Kluijt I, Nagtegaal T, Verhoef S, Bleiker EM. Genetic testing in Li-Fraumeni syndrome: uptake and psychosocial consequences. J Clin Oncol.

2010;28(18):3008-14.

23. Cannon Albright LA, Thomas A, Gholami K, Rowe K, Jacobsen M, Skolnick MH. Familiality of Cancer in Utah. Cancer Res. 1994;54(9):2378-2385. 